Research Article

\title{
Delphi Method Combined with Computer-Assisted Teaching of Information Fusion to Explore Intelligent Physical Education in Colleges and Universities
}

\author{
Mingcan Liu (i) \\ Department of Sports, Civil Aviation University of China, Tianjin 300300, China \\ Correspondence should be addressed to Mingcan Liu; mcliu@cauc.edu.cn
}

Received 17 August 2021; Revised 15 September 2021; Accepted 24 September 2021; Published 25 October 2021

Academic Editor: Sang-Bing Tsai

Copyright ( $\odot 2021$ Mingcan Liu. This is an open access article distributed under the Creative Commons Attribution License, which permits unrestricted use, distribution, and reproduction in any medium, provided the original work is properly cited.

\begin{abstract}
The research aims to provide ideas for improving college students' physical quality in China. Firstly, the theories of the Delphi method and Computer-Aided Instruction (CAI) are introduced, and the basic process of the Delphi method is deduced. Secondly, the intelligent college Physical Education (PE) is discussed under the Delphi method combined with CAI, and the CAI-added Delphi method-based PE teaching model is proposed. The model verification results show that the proposed model presents an excellent teaching effect by combining intuitive expression and flexible courseware with higher teaching efficiency. As a result, students who have difficulty mastering the essentials of sports actions have shown significant improvement after CAI PE. Meanwhile, the teaching method of CAI is more flexible compared with traditional methods, especially, on-blackboard projection. The proposed teaching model is more vivid and memorable thanks to the video presentations voiced over by teachers. CAI can significantly improve students' interests in sports and their sports performance. Meanwhile, the CAI PE teaching system is more suitable for theoretical knowledge instruction by replacing the dull teacher-centered word interpretation with vivid and intuitive video presentations voiced over by teachers. Therefore, the proposed CAI-added Delphi method-based PE teaching model has certain feasibility and plays a significant role in promoting PE teaching quality in China.
\end{abstract}

\section{Introduction}

The 21st century is witnessing the integration of various state-of-art technologies into education; in particular, Computer-Aided Instruction (CAI) is widely used for the traditional teaching reform. Under the deeply rooted examoriented educational background, the physical quality of Chinese students is worrying. It has been reported that most Chinese undergraduates cannot even do ten push-ups. Therefore, Physical Education (PE) is attracting the attention of the government and people from all walks of life [1]. In particular, CAI is a vivid and flexible new teaching concept based on the foundation of the current information age, namely, the computer. Thus, the introduction of computer technologies into PE is feasible and very advantageous over the traditional teaching model. For example, CAI can combine animation, pictures, and music through computer technologies to arouse students' interest in learning. College $\mathrm{PE}$ includes theoretical knowledge and practical skills, of which the practical PE curriculum is based on students' theoretical knowledge, while the theoretical knowledge can be transformed into practical skills vividly through CAI. CAI PE teaching model can improve students' attention and mobilize their learning enthusiasm by providing them with movie-like videos [2]. Delphi method is an expert investigation method widely used in the fields of prediction and evaluation. Delphi method can be used to predict the trend and direction of students' development to guide teaching and improve teaching quality. Additionally, experts and professors in many fields in colleges and universities also ensure the smooth development of the Delphi method, and the teaching system of colleges and universities also ensures the responsibility of experts participating in the Delphi method. At present, there are studies on education quality 
optimization through the theory of CAI or the Delphi method. Yet, the single-method optimization has shown less satisfactory performance in the education quality: the CAI lacks the integration with the cutting-edge technologies and ideas of the times, while the Delphi method predicts the development trend of education not as good as the CAI.

Chen et al. contended that the traditional education model could not meet the requirements of the times. He proposed a college PE teaching model based on virtual crowd simulation and digital media and constructed the corresponding system. Under actual teaching evaluation, the proposed model performed well [3]. Ming et al. studied the interaction between teachers and teaching content in college $\mathrm{PE}$ and their impact on students' physical activity levels, finding that theoretical knowledge and ordinary activities contributed to students' sitting physical activities, while action practice and games could predict sitting physical activities [4]. Ricardo et al. analyzed the impact of SEM (Sport Education Model) on students' learning motivation, discovering that there was a significant correlation between self-efficacy and motivation. SEM provided students with more opportunities to determine their motivation in PE [5].

The Delphi method can guide and predict students' developmental direction. The addition of CAI also greatly expedites the development of the Delphi method and the statistical analysis of results. Thus, the CAI-added Delphi method can combine the classical optimization methods with the cutting-edge technologies and ideas of the times, thereby complementing the shortcomings of the singlemethod education system. Thereupon, this paper briefly describes the basic theoretical knowledge of the Delphi method and CAI, as well as their applications in Intelligent $\mathrm{PE}$ in colleges and universities. Consequently, a CAI-added Delphi method-based PE teaching model is implemented. Then, a Questionnaire Survey (QS) is conducted on the attitudes of teachers and students toward the proposed CAIadded Delphi method-based PE teaching model, and the students' performance level before and after the model implementation is statistically analyzed. The results can improve the quality of college PE in China, as well as the physical quality of college students, and can contribute to the development of college PE in China.

\section{Delphi Method and PE under CAI}

2.1. Delphi Method. Delphi method is an expert investigation widely used in the fields of prediction and evaluation. Delphi method judges or evaluates the research problems based on personal expertise and expert meetings. Distinctively, it can collect the opinions of experts without meeting them and integrate the experience and intelligence of the society $[6,7]$. The Delphi method has originated in 1946. Its process reads as follows: the investigator initiates and draws up an investigation plan and sends it to experts for opinions, and the experts will discuss it in secret. The opinions collected twice will correctly guide the investigation findings, as shown in Figure 1.

In essence, the Delphi method utilizes collective wisdom to forecast an event at a relatively accurate level through the

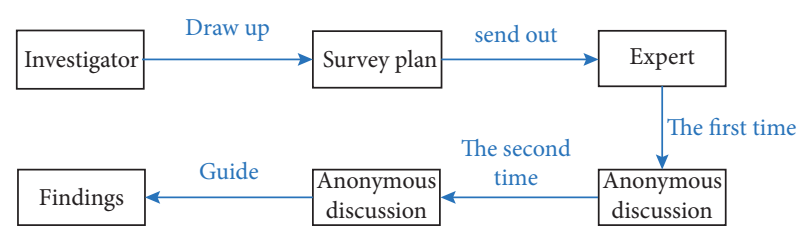

FIGURE 1: Delphi method initiation process.

subjective opinions exchange within the panel of experts. Delphi method aims to forecast the development law of certain things rather than the utmost accuracy and control the possible development path of things through the link of experts' exchange. Different from other forecasting approaches, the Delphi method can effectively coordinate and converge the opinions of experts from various fields using the mechanism of multiple feedback and anonymous discussion and analysis, which makes it possible to achieve more effective solutions against some difficult problems [8]. Thus, the Delphi method can obtain accurate extension suggestions for the development of the method. The specific procedures for its implementation are divided into group establishment, expert collection, research design, research, and statistical analysis, as shown in Figure 2.

(1) Group establishment: it is the primary link of the Delphi method and is responsible for the whole forecast discussion process, including the evaluation and estimation of the forecast objectives, the selection and collection of experts in related or nonrelated fields, the distribution and recovery of expert opinions and QS, and the statistical analysis of the collected results. (2) Expert collection: it is also very important. Experts with academic authority are selected, who are required to be serious and responsible for evaluation and QS answering, submit their opinions timely, and revise their earlier answers in light of the feedback from other members in the panel [9-12]. Additionally, the number of selected experts also impacts the final results, as shown in Figure 3.

Figure 3 reveals that the accuracy of the forecast results is the function of the number of invited experts: given a small number of experts, collected opinions are not comprehensive enough, so the forecast results are of little reference value; when the number reaches about 20 , the forecast accuracy peaks; yet, when the expert number further increases, their opinions are difficult to converge, and the forecast time will spike, resulting in fatigue even boredom of some experts, thus affecting the final forecast results [13]. Notably, the research design is of extraordinary significance to the Delphi method; on the one hand, well-design research can provide experts with detailed research background and the specific process of the Delphi method, so that experts can have a clear understanding of the forecast work; specific examples can be enclosed along with the flowchart to help experts master the workflow of the Delphi method quickly; on the other hand, the design of research questions must be brief and clear with abundant graphs or tables to facilitate reading and minimize expert fatigue and boredom, thereby obtaining objective, fair, and accurate forecast results [14-16]. Usually, a complete predict result demands at least 


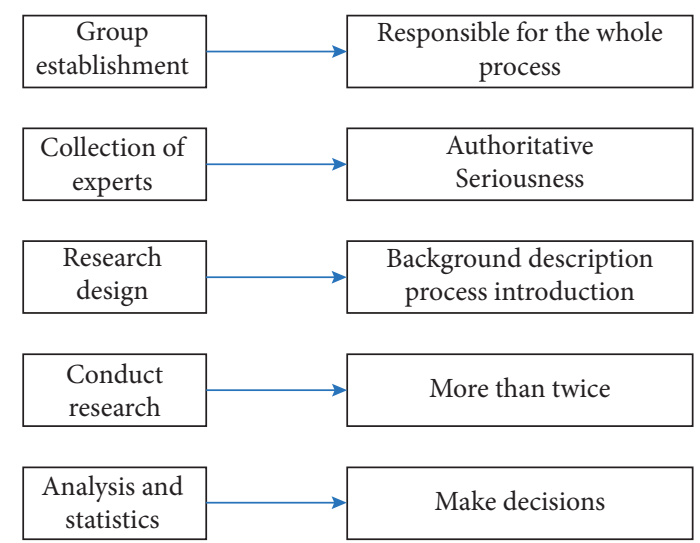

Figure 2: Specific implementation of the Delphi method.

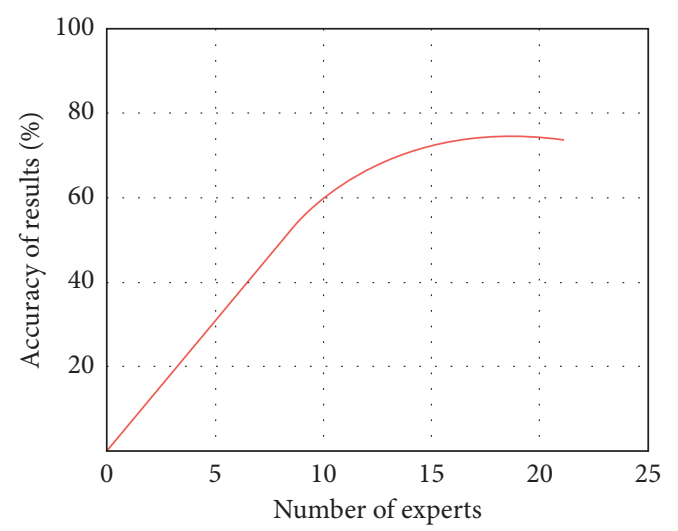

FIGURE 3: Influence of the number of experts on the final forecast in the Delphi method.

two rounds of expert QS: the first QS is more flexible, where experts are left to decide for themselves; the first-round recovered QS will be statistically analyzed, and the results will be distributed among members in the expert panel together with the next-round QS. Importantly, the Delphi method collects experts' opinions and distributes statistical feedback multiple times until satisfactory forecasts are obtained [17]; this process generally takes twice, after which relatively consistent forecast opinions and statistical analysis can be obtained; if the difference between the two-round results is too large, the results will be integrated for statistical analysis, and a follow-up opinion collection and feedback link might sustain, as shown in Figure 4.

Delphi method is an anonymous expert discussion. Compared with other forms of trend forecasting methods, the Delphi method features anonymity, feedback, effectiveness, statistics, and professionalism. The experts of the Delphi method do not contact each other, thus providing a high degree of autonomy, and each expresses their unique opinions, avoiding the herd mentality and possible quarrels and conflicts from disagreement. At the same time, the Delphi method repeated investigation and statistics to obtain unified satisfactory results for all experts. Each analysis result will provide references for experts in the next round of investigation.
The experts' opinions will eventually converge to a common result, namely, the correct answer [18, 19]. Additionally, the Delphi method is professionally reliable with authoritative experts from various fields. The specific characteristics of the Delphi method are shown in Figure 5.

The Delphi method has its unique advantages. Firstly, the process is simple and logical; secondly, the expert panel is allowed sufficient time to consider the research questions for more precise replies; thirdly, every round of QS is issued along with the statistical analysis of the previous QS to encourage experts to revise their answers in light of replies of other members in the panel, thereby ensuring a unified reply; fourthly, anonymity avoids the defects of many traditional methods, such as the forecast deviation from herd mentality. Finally, the mathematical model is used for statistical analysis of the results to obtain higher reliability, as shown in Figure 6.

2.2. CAI. CAI is born of the rapid development of the computer and the Internet. At a time of rapid change, traditional education can no longer readily serve the demands of teaching and learning. Thus, there is a need to combine the traditional education model with the mainstream of the times to cultivate qualified modern social talents. Besides, informatization or digitalization has become the inevitable trend of traditional educational reform, which is reflected in many aspects $[20,21]$. The blackboard-centered traditional teaching method is inflexible and presents very limited content under today's information explosion age, which seldom involves state-of-art information or technologies. Not surprisingly, students are not interested in the traditional teaching method that lacks novelty, where the role of teachers is predominant in teaching quality and students' learning enthusiasm. By comparison, the Delphi method combined with CAI has the following advantages. First, the network-based resource sharing can well-tailor the needs of the education system, and the CAI pattern can help students master knowledge more efficiently; second, the flexible CAI pattern is believed to be a must-do choice for educational reform against the tremendous pace of the times, which can greatly improve students' comprehensive quality; third, the information explosion has been changing and complicating the global socioeconomic environment, under which teachers' knowledge system must be updated all the times. Surely, competent teachers are more likely to cultivate high-quality talents; fourth, the CAI obsoletes the cramming educational pattern by providing more guidance. It has been argued that interest is the best teacher, which is what CAI holds to inspire students to learn independently and happily, thereby uplifting the quality of education, as shown in Figure 7.

Nowadays, more cutting-edge science and technologies, such as AI (Artificial Intelligence), are seeing their applications in people's life, work, and study, thanks to which the traditional CAI pattern is constantly upgraded. In particular, the concept of integrable ware is introduced in CAI [22]. Specifically, the key contents in the courseware can be divided into video, music, and pictures. This flexible and 


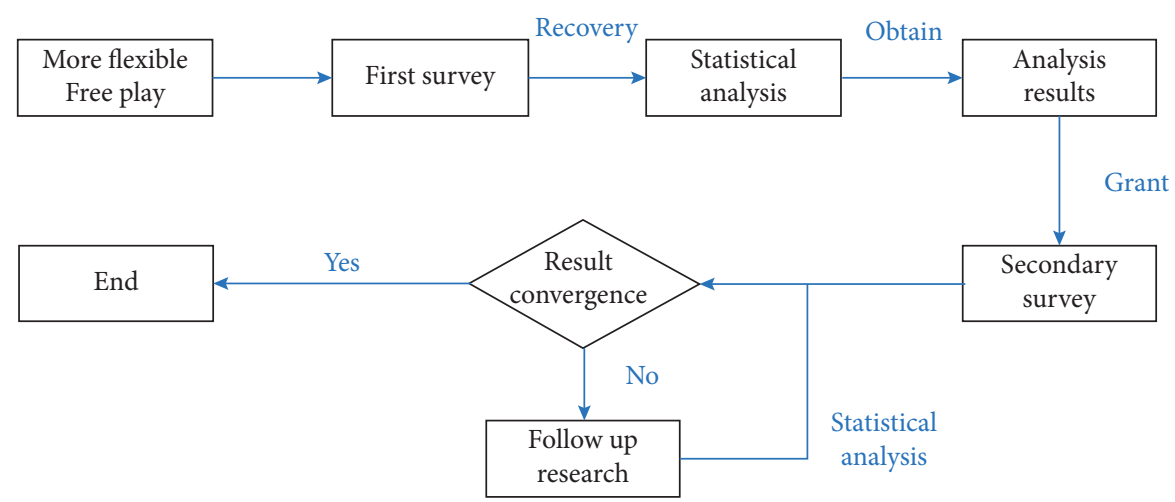

Figure 4: Main links of Delphi method.

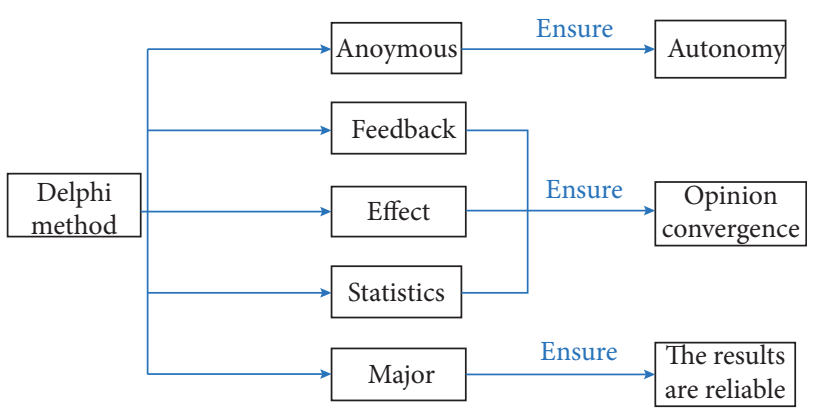

Figure 5: Characteristics of Delphi method.

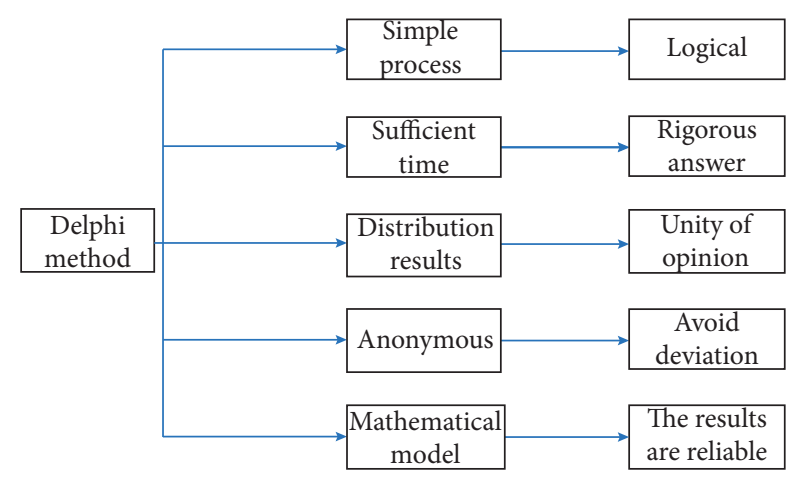

Figure 6: Advantages of Delphi method.

fragmented (integrable) teaching courseware can be randomly combined to allow different teachers to display. The advantages are summarized as follows. First, the fragmented courseware ensures the flexibility of teaching and reflects the characteristics of different teachers, avoiding simple bookparaphrasing. Second, the fragmented courseware is independent of the teaching system and is not affected by the version update of teaching materials. Thus, it applies to any classroom situation. Thirdly, integrable ware can be freely combined to expand its application. Fourth, integrable ware is not affected by external ideas, and the ideas expressed can be controlled by teachers, as shown in Figure 8.

In fact, theory always comes before practice in social development, which is especially the case for some Chinese colleges and universities who use CAI as a mere formality by photocopying the books to the computer. Thus, students' learning experience has been more or less the same as the traditional means; only the blackboard has been replaced with a shiny monitor, let alone the classroom environment that is still boring and vigorless. Worse still, teachers may be reluctant to update the courseware contents, so students' knowledge lacks practical significance; secondly, the use of CAI has not significantly improved students' learning enthusiasm, teaching still focuses on display and explanation, and students do not have a sense of participation; finally, the application of CAI is almost uniform regardless of discipline difference and lacks novelty, as shown in Figure 9.

Given the above shortcomings, relevant suggestions are given here to avoid futile efforts in educational reform. Firstly, there is a need for colleges and universities to pay more attention to the CAI teaching model to defend against formalities. Some teachers have high aspirations for the new teaching model, but their skills for courseware-making are terrible. Thus, targeted skill training for teachers can be conducted. Meanwhile, the teachers' courseware content can be comprehensively reviewed and evaluated against the pace of times and latest technologies. Secondly, since students lack the sense of participation, more classroom interactions can be designed. Teachers are encouraged to select students randomly to inspire students more focused on the classroom. Teachers also can encourage students to design specific courseware one by one and present them in front of the class, which can greatly enhance students' sense of participation in the CAI teaching model while mastering the knowledge points. Finally, teachers can be trained with the diversification of CAI in courseware design for different disciplines. For example, different colors can be used to represent different disciplines, or objects with representative significance to the discipline can be selected as icons at the beginning and end of the courseware. In CAI classrooms, the difference between disciplines is mainly reflected in the way teachers explain and the expansion direction of classroomderived knowledge. At present, colleges and universities are exerting more efforts in fusing cutting-edge knowledge into classroom teaching for professional courses, which is also an embodiment of the difference between disciplines.

Although there are still some problems in CAI application, its positive role in innovating the traditional teaching 


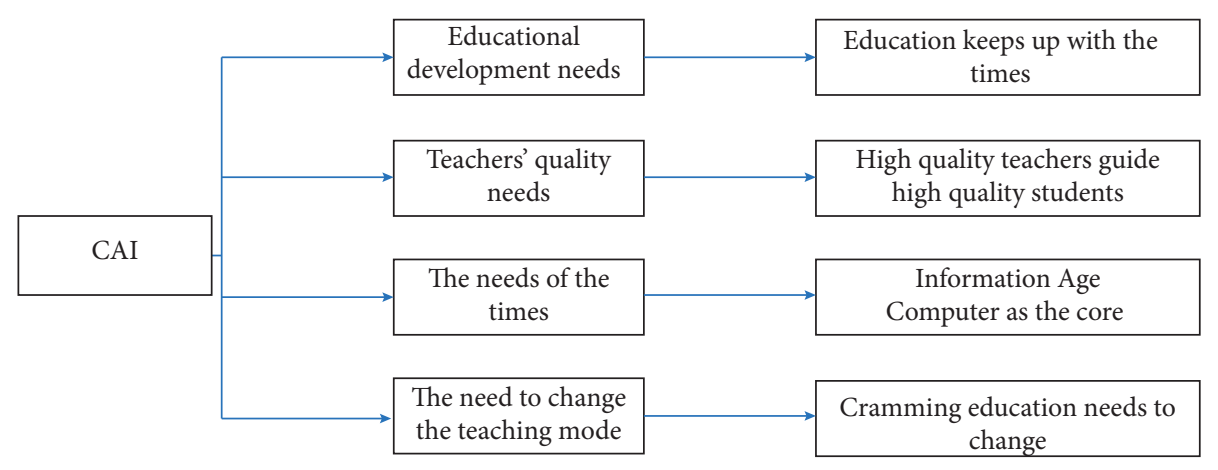

FIgure 7: The inevitability of CAI.

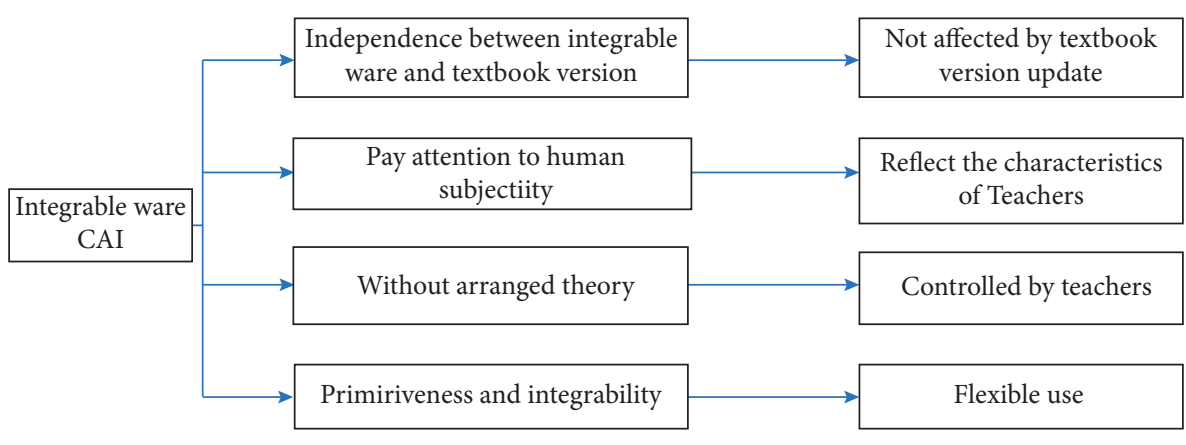

Figure 8: Advantages of integrable ware CAI.

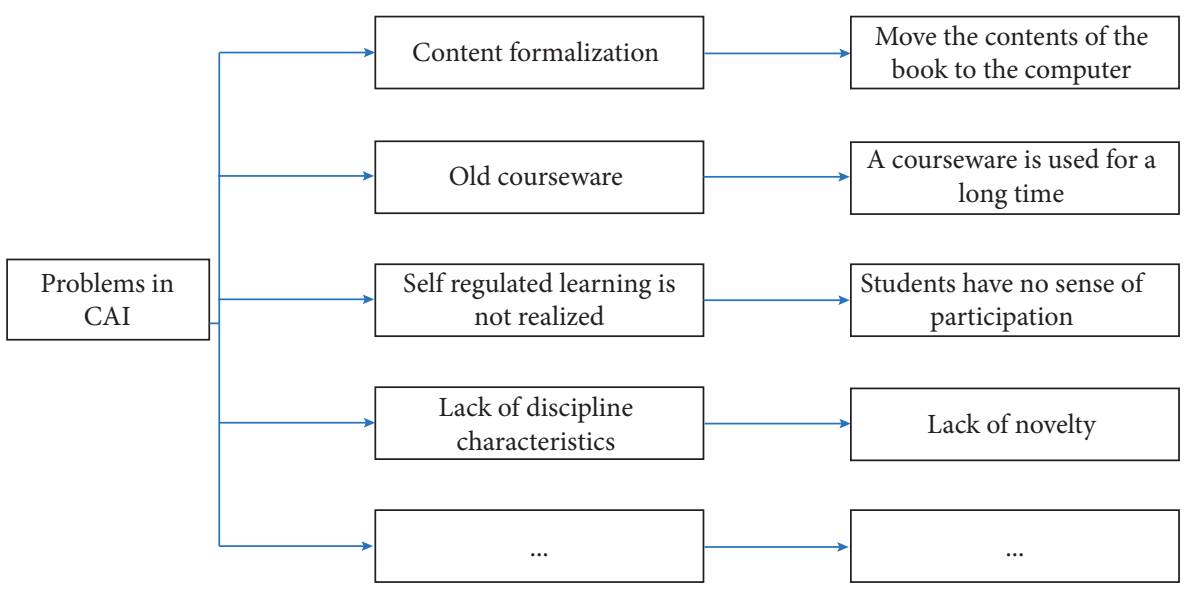

Figure 9: Current problems of CAI.

pattern is undeniable by bringing flexibility and vividness to the education system and pointing out the orientation for education reform. It is believed that, in the future, CAI can be better integrated with the education system and achieve better teaching results.

2.3. Information Fusion. Information fusion, also known as data fusion, is a process of associating the data or information from single or multiple information sources. Information fusion can accurately forecast the information, such as the location, and evaluate the development trend and possible results, thereby improving the results in continuous self-correction. Its essence is to analyze and process the sensor-acquired information by the computer and use it for decision-making and forecast. Therefore, the basis of information fusion is the multisensor system, and its processing object is the obtained multisource information, and its core is the optimization and processing of information. In other words, information fusion is to analyze and process the multisource information obtained from multisensors by computer, thereby obtaining the expected synthetic information.

With the continuous innovation of science and technology, a single sensor has been unable to meet the monitoring needs of various physical quantities. As a result, 
multisensor technology has spread quickly. Compared with a single sensor, a multisensor can complete information complementarity at various levels thanks to the diversified sensor performance to obtain more effective information. Thereupon, the obtained information can be fused to further improve its accuracy. The information fusion technology can well adapt to such demands and refine the reliability and intelligence of physical quantity monitoring for various systems. Information fusion technology appears with the development of radar information processing and intelligent automation system. It can collaboratively utilize multisource information, enhancing the monitoring accuracy and comprehensiveness of the same target. The information fusion in the command automation system can comprehensively process the association data information from multiple sensors to obtain accurate forecast information and complete the evaluation of development trends and threats timely.

Generally, there are three methods for information fusion, namely, embedded constraint method (the most basic embedded constraint method includes Bayes estimation and Kalman filter), evidence combination method (the commonly used evidence combination method includes probability statistics method and Dempster-Shafer evidence reasoning), and Artificial Neural Network (ANN) method.

Here, the ANN method is employed for information fusion. Through the simulation of human brain structure, the corresponding model can be established for intelligent task processing. This information fusion method has the following characteristics. Firstly, the sensor information obtained by the network can be fused by a learning algorithm. Secondly, the ANN method can use the information of the external environment to obtain knowledge automatically. Additionally, through learning and reasoning, more complex relationships can be fused into accurate signals that the system can understand. Finally, the ANN method has fast information processing speed. The steps of information fusion by ANN method are as follows:

(1) According to the information fusion form of multisensor, the topology is selected

(2) The information of each sensor is comprehensively processed, and the input function is defined as the mapping function of relevant units. The statistical law of the environment is fed back to the structure of the network through the interaction between the ANN and the environment

(3) The output information is learned and understood, weight parameters are assigned, and information fusion is completed

2.4. CAI-Added Delphi Method-Based PE Teaching Model. At present, there are studies on the optimization of education quality based on the Delphi method or CAI theory, respectively, which have shown an unsatisfactory optimization effect. The Delphi method optimization lacks the integration with the cutting-edge technologies and ideas of the times, while CAI optimization presents poor predictability for educational development trends than the Delphi method optimization. The recent decades have witnessed the rejuvenation of the great Chinese nation, with which many local brands and technologies are leading the world. However, the physical quality of Chinese college students has declined substantially, which calls for intense attention from all social spheres. PE is a key link in promoting modern education [23]. The application of CAI in PE is of great significance and with well-grounded feasibility. The rich knowledge base and flexible use of computer media in CAI agree with the development of PE. The integration of CAI and PE breaks through the limitations of traditional PE and avoids the teaching deviation from different teachers. Additionally, the introduction of CAI improves students' learning enthusiasm. In particular, college PE includes both theoretical knowledge instruction and practical activities, of which the practical activities are more popular among students under heavy pressure from theoretical courses, while the transmission of PE theoretical knowledge has also been visualized through CAI. As a result, students feel like enjoying movies and videos during theoretical courses. This can improve students' attention and mobilize their learning enthusiasm [24]. At the same time, some students may not fully understand the essentials of sports movements given a single teacher interpretation, which can be compensated by CAI. Following the explanation of video animation and schematic diagram, students can master the sports movement essentials. Under the combination of CAI with practical teaching, students can quickly assimilate the new knowledge. Further, the Delphi method can be used to predict students' developmental trends, thereby evaluating the teaching effect. In the context of the campus environment, experts and professors are almost omnipresent, which smooths the path of the Delphi method in colleges and universities. Besides, the academic and humanistic environment of colleges and universities ensures the sense of responsibility in the panel of experts in the Delphi method, thus improving the prediction accuracy, and computer assistance has made the process of the Delphi method and the statistical analysis of results more convenient $[25,26]$. Thereupon, a CAI-added Delphi method-based PE teaching model is proposed here, and its structure is shown in Figure 10.

\section{Results Investigation and Analysis}

The feasibility of the proposed CAI PE model is investigated through the QS that collects the attitudes of 10 PE teachers and 200 students toward the CAI-added Delphi methodbased PE teaching model. The specific information of the respondents is shown in Figure 11.

3.1. QS on Teachers'Attitude. The attitude of teachers toward the CAI-added Delphi method-based PE teaching model is investigated, as shown in Figure 12.

Figure 12 illustrates that most teachers can accept the CAI-added Delphi method-based PE teaching model, and 6 teachers think that the PE teaching effect is good. Still, 5 


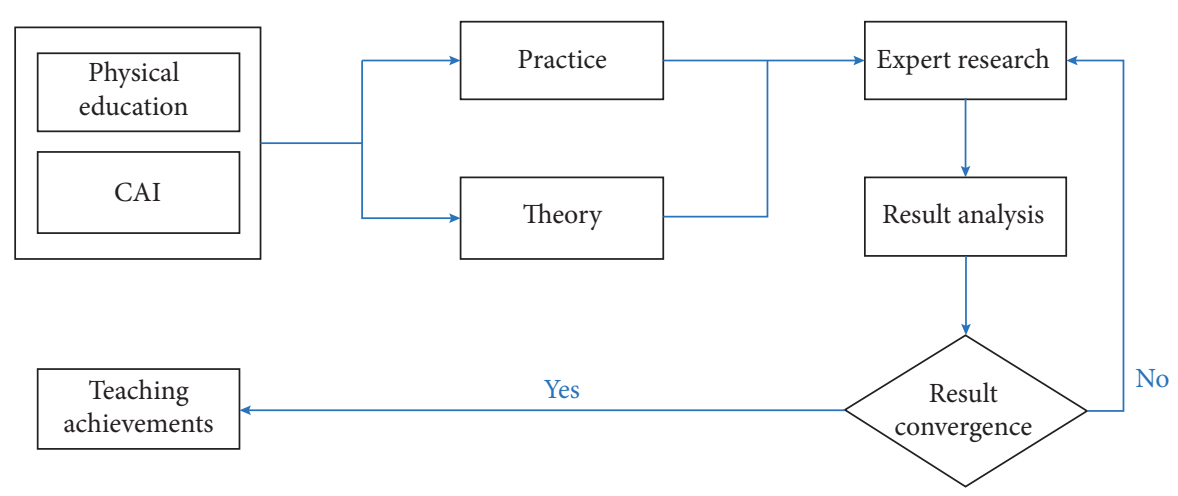

FIgURe 10: CAI-added Delphi method-based PE teaching model.

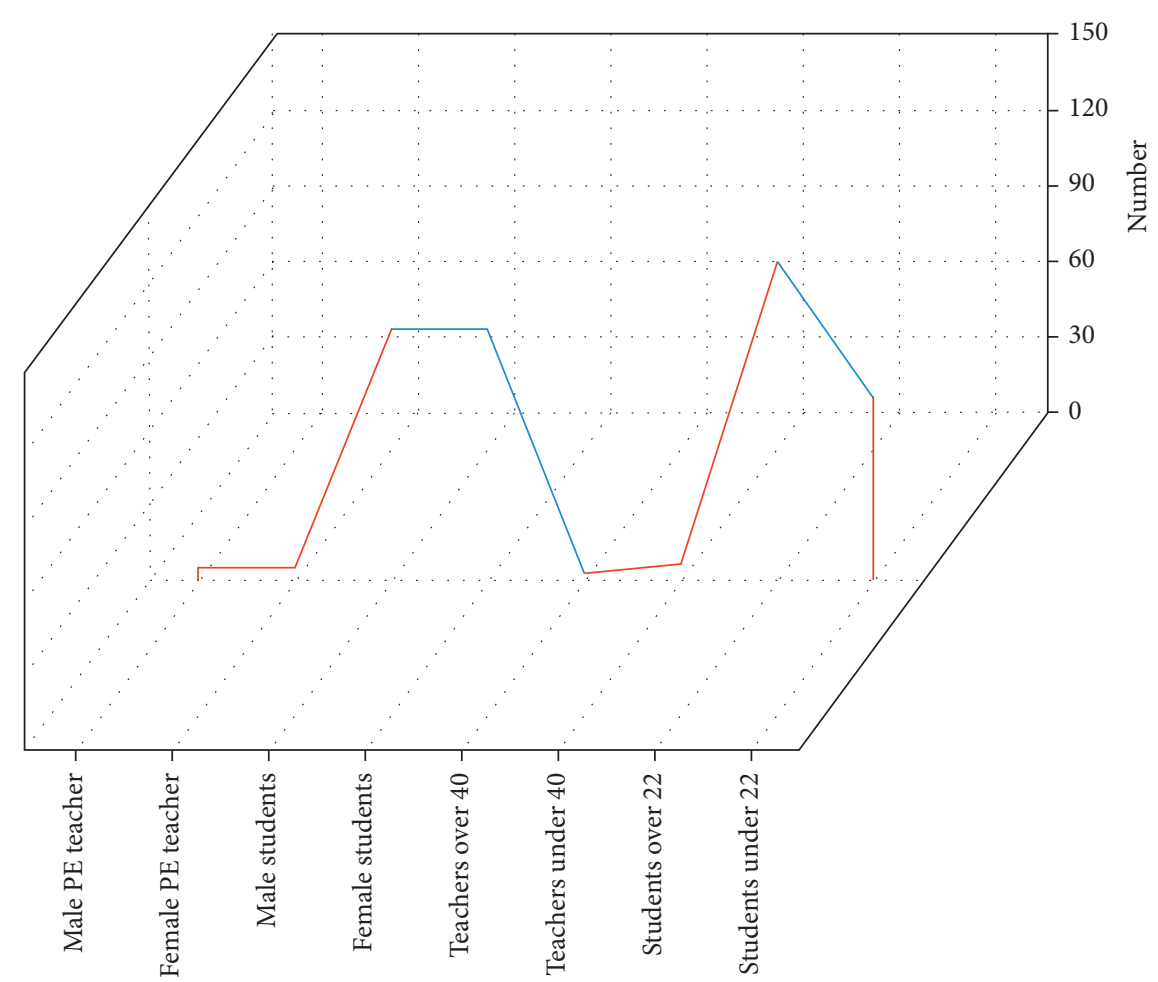

Figure 11: Composition of respondents.

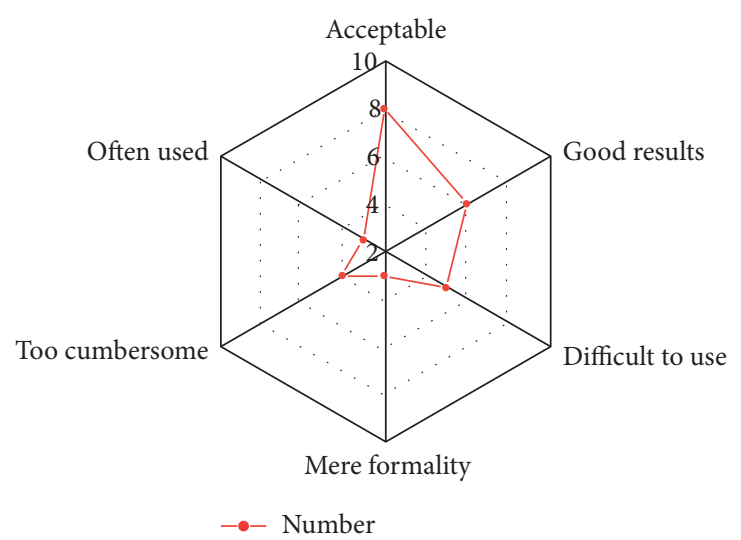

Figure 12: Teachers' attitude toward the CAI-added Delphi method-based PE teaching model. 
teachers think that the CAI-added Delphi method-based PE teaching model is difficult to use, and 3 teachers think that the proposed method is more formal than feasible. Meanwhile, 4 teachers think that the proposed method is too cumbersome to use frequently in the actual teaching, which is reflecting in the development of the Delphi method and the time consumption of expert evaluation. Overall, only 3 teachers often use the proposed CAIadded Delphi method-based PE teaching model, and over half of the teachers seldom use the proposed teaching model. According to the QS results, some teachers believe that the CAI-added Delphi method-based PE teaching model has a good teaching effect. Its intuitive expression and flexible courseware combination have greatly improved the teaching efficiency. The performance of students who cannot master the essentials of sports movement has also improved significantly after CAI PE teaching. These teachers with positive feedback are generally young, proficient in computer operation, and sophisticated with courseware design and operation. Therefore, the CAI-added Delphi method-based PE teaching model can well lend itself to the classroom and achieves good results.

However, some teachers rarely use the CAI-added Delphi method-based PE teaching model. They use CAI for theoretical teaching only in bad weather when practical teaching is unfeasible, mainly, in the form of sports event videos or some PE training videos. Students' interest in this form of CAI PE teaching is not very high, so the teaching effect is limited. These teachers with negative feedback are generally older, lack computer skills, and are clumsy in courseware design and operations. Although they have a positive view on the combination of $\mathrm{PE}$ teaching with emerging knowledge, given their age, the proposed teaching method is not easy to familiarize. The specific investigation on the CAI training of the college PE teachers is shown in Figure 13.

Mostly, PE teachers learn CAI and other new teaching methods through self-study and are willing to accept relevant training courses. However, colleges and universities often ignore the CAI PE teaching method, so teachers do not often use CAI for auxiliary teaching even if the application of CAI is recognized by most of them. Occasionally, some teachers will resort to CAI to play videos on some sports events in bad weather. The above analysis shows that the proposed CAI-added Delphi method-based PE teaching model is feasible. Most teachers' recognition of the proposed method guarantees its application and development, and a small number of teachers who do not recognize it will get used to it sooner or later. Hence, CAI has been closely combined with the education system, and then, the application of CAI will become more frequent and mainstream in the future.

3.2. QS on Students' Attitudes. The attitude of students in the CAI-added Delphi method-based PE teaching model is investigated, and the investigation results are shown in Figure 14.

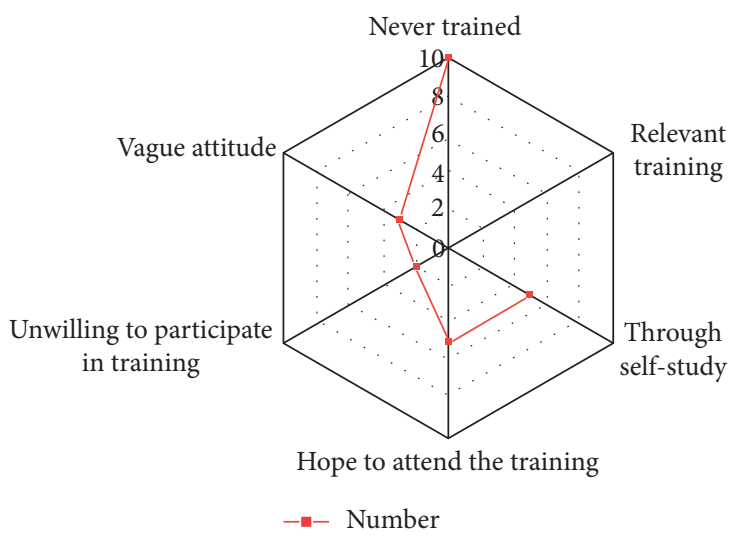

FIgURE 13: Investigation on CAI training of college PE teachers.

Figure 14 displays that 36 students are very satisfied with the proposed CAI-added Delphi method-based PE teaching model. These students are highly satisfied with the vividness of CAI PE teaching courseware and the intuition of teaching video, and they have highly praised the music in the teaching video, getting themselves immersed in it physically and mentally, with a full sense of experience. Meanwhile, 57 people are satisfied with the proposed method. They recognize its teaching effect and prefer this teaching pattern; By contrast, 89 students are relatively satisfied, accounting for the largest proportion of the respondents. They do not reject the proposed teaching method, and their attitude toward CAI courseware is relatively stable. Additionally, 18 students are not satisfied with the proposed teaching method. They prefer relatively free outdoor practical courses, but the proposed teaching method occupies part of the outdoor teaching time. In terms of the teaching effect, most students think the proposed teaching method has a specific effect. A few students think that CAI courseware is no different from textbooks: once the video clip is skipped, they cannot review the content, and when the content is too much, they do not have enough time to take notes. Thus, they do not recognize this teaching method. The specific expression of students' attitudes is shown in Figure 15.

Figure 15 shows that most students like innovative teaching methods different from traditional teaching. They hope that the CAI PE teaching model can be more flexible. For example, the classroom video presentations can be voice-over by teachers. Compared with traditional blackboard presentations, the proposed method is more vivid and memorable. Those students who are dissatisfied with the proposed method think that CAI courseware is too monotonous, with too many words and few intuitive picture symbols, which is no different from the textbook. On some occasions, students are not allowed enough to watch the videos to take notes when teachers alter the slides or videos too frequently, which is not conducive to the mastery of knowledge. This is mainly due to the inappropriate CAI content design rather than the defects of the CAI teaching model. Students prefer the concept of the CAI-added Delphi method-based PE teaching model, but its content is often 


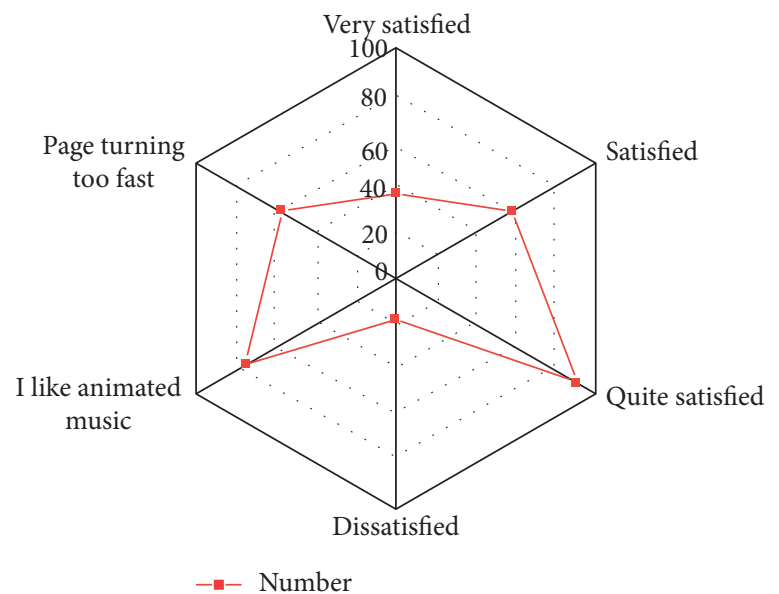

FIGURE 14: Students' attitude toward the CAI-added Delphi method-based PE teaching model.

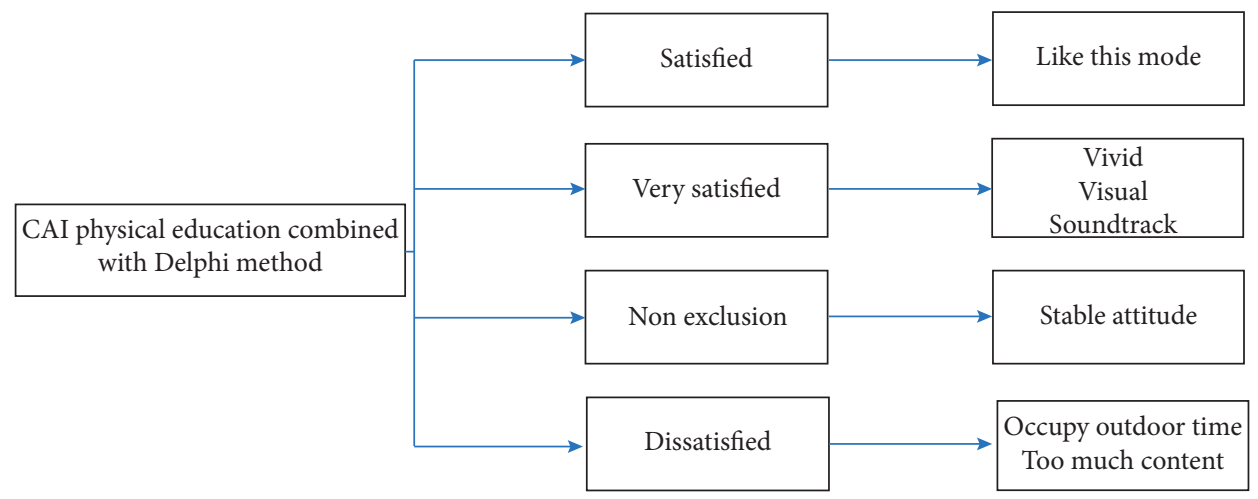

FIGURE 15: Students' specific attitude on CAI-added Delphi method-based PE teaching model.

disappointing. Therefore, attention should be paid to the learning effect of students, as well as to the teaching effect of teachers. Further, the teaching courseware should be upgraded timely to ensure its novelty and keep up with current events and, thereby, attract students' attention and enhance their learning interest. Students are the main beneficiaries of the combination of the Delphi method and the CAI PE teaching model. The positive attitude of most students also proves the feasibility of the proposed CAIadded Delphi method-based teaching model. No matter how excellent the teaching method is, without the cooperation of students, it will be difficult to exert its full effects.

3.3. Student Classroom Performance Comparison. After a semester of PE classroom observation, the classroom performance is statistically analyzed for the experimental group and the control group. The results are shown in Figure 16.

Obviously, compared with the traditional classroom, the CAI-added Delphi method-based PE teaching model has better classroom performance, students' attention is more concentrated, and students' participation degree is much higher. Meanwhile, students' absent-minded behaviors have significantly reduced. This shows that the proposed CAIadded Delphi method-based PE teaching model has better classroom discipline and a better learning atmosphere. Students' behaviors, such as small talk, noisiness, and naughty play, may hinder their classmates from concentrating on learning, while teachers have to spend lots of time and energy handling these in-class disturbances, which will reduce teaching effectiveness. Therefore, under the proposed CAI-added Delphi method-based PE teaching model, the teaching effect is improved with a more self-disciplined classroom environment.

\subsection{Effect of CAI-Added Delphi Method-Based PE Teaching} Model. The actual effect of the CAI-added Delphi methodbased PE teaching model is verified through a practical investigation on the students, and the results are shown in Figure 17.

Figure 17 implies that the CAI-added Delphi methodbased PE teaching model can significantly improve the cultivation of students' interest in sports. Most students have increased their interest in sports courses after participating in the new PE teaching model, while some students' interest in learning has reduced, which is worth noting and should be avoided. At the same time, the new PE teaching model has significantly improved the students' sports performance, and nearly half of the students' performance has increased. 


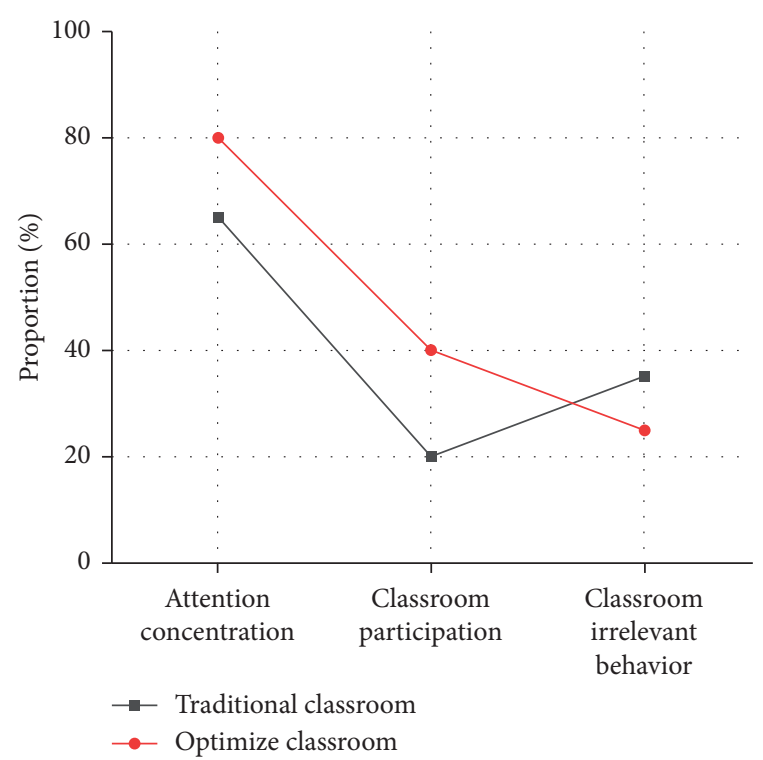

FIGURE 16: Classroom performance statistics.

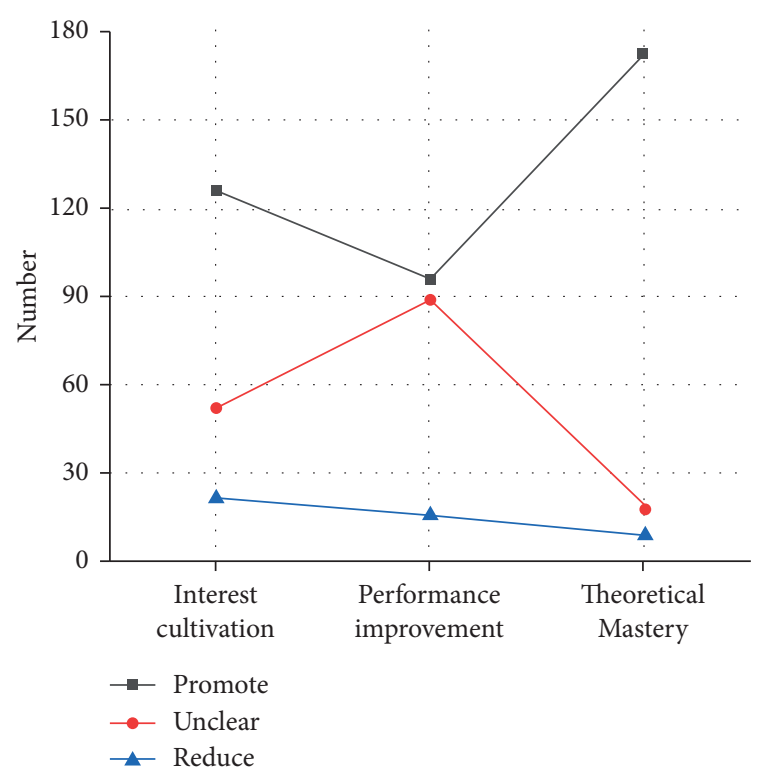

FIGURE 17: Research on the effect of CAI-added Delphi methodbased PE teaching model.

However, some students have no idea what is going on, and for these students, CAI is not helpful to improve their sports performance. Additionally, 173 students have improved their mastery of theoretical knowledge, indicating that the new PE teaching model may be more suitable for theoretical knowledge teaching, and its vivid classroom model can alleviate the boredom of the traditional classroom model.

Students are always attracted by new things, and the rich and colorful CAI classroom can arouse students' desire to learn. However, in practice, some teachers' courseware is no different from traditional blackboard writing, which leads to students' lower evaluation of CAI. Compared with Microsoft's PowerPoint Presentation (PPT) files, animation and music pictures are more favored by students. The innovation of the PE curriculum by adding the CAI is also reflected in the change of the traditional learning pattern of students from listening in class and exploring by themselves after class to more initiative in-class learning and classroom involvements. Consequently, students can also study independently in the classroom, which plays an important role in their sports performance, especially, in the mastery of theoretical knowledge.

\section{Conclusion}

The physical quality of college students in China has been on a decline. Following the introduction of the Delphi method and CAI, the intelligent college PE is studied under the Delphi method combined with CAI. Thereupon, a CAIadded Delphi method-based PE teaching model is proposed. Experimental results show that the CAI-added Delphi method-based PE teaching model does have a good teaching effect. Its intuitive expression and flexible courseware combination greatly improve the teaching efficiency. Some students who cannot master the essentials of sports movement have also improved their sports performance significantly after participating in the proposed PE teaching model. However, some students are not optimistic about this teaching method. Some teachers make courseware with single content, too many words, and insufficient pictures and animation. At the same time, the teaching method of CAI should be more flexible. For example, the video presentations can be voiced over by teachers. Compared with the traditional blackboard presentation, the proposed teaching model is more vivid and memorable. But some teachers turn the clips too frequently, and students cannot take notes timely or master the knowledge points. Additionally, CAI can significantly improve the cultivation of students' sports interests and students' sports performance. Still, there are some shortcomings: although the fusion method, namely, the CAI-added Delphi method-based PE teaching model, has largely overcome the defects of a single-method optimization, it is still affected by teachers themselves who are responsible for the whole educational process. Additionally, the influence of teaching equipment cannot be ignored, which seems inevitable. In the follow-up study, it is hoped that the impact of teachers' teaching methods, teaching standards, and teaching equipment will be studied on the teaching quality, thereby proposing a long-term effective fusion method of the Delphi method and CAI. The proposed CAI-added Delphi method-based PE teaching model can significantly promote $\mathrm{PE}$ teaching and provides a reference for the application of CAI in the field of PE.

\section{Data Availability}

The labeled dataset used to support the findings of this study is available from the corresponding author upon request.

\section{Conflicts of Interest}

The author declares no conflicts of interest. 


\section{References}

[1] M. D. Sylvain, I. O. Jean, F. B. Gabin, M. J. M. Suzie, and M. L. De-Consentie, "Influence of teaching style on pupils engagement in physical and sport education in grammar school of brazzaville," Advances in Physical Education, vol. 09, no. 4, pp. 303-313, 2019.

[2] C. Luguetti, P. Lopes, D. R. D. S. Sobrinho, M. V. Carbinatto, and A. MacPhail, "The complexity, tensions and struggles in developing learning communities throughout a Sport Education season," European Physical Education Review, vol. 25, no. 4, pp. 1075-1092, 2019.

[3] M. Zhou, Y. Wang, Z. Tian, Y. Lian, Y. Wang, and B. Wang, "Calibrated data simplification for energy-efficient location sensing in internet of things," IEEE Internet of Things Journal, vol. 6, no. 4, pp. 6125-6133, 2019.

[4] C. S. Ming, S. K. W. Raymond, L. F. L. Elean, H. S. C. Amy, S. Cindy, and Y. K. Ho, "Predictors of physical activity levels in university physical education implementing sports education," Journal of Sports Science \& Medicine, vol. 20, no. 3, pp. 516-524, 2021.

[5] T. Ricardo, D. Alves Madalena, F. Tiago, A. Gonçalo, G. Leonor, and I. Andreas, "Impact of sports education model in physical education on students' motivation: a systematic review," Children, vol. 8, no. 7, p. 588, 2021.

[6] M. M. Pilar, C. Antonio, H. Peter, L. Arias Estero José, R. Araújo, and I. Mesquita, "Grouping students by skill level in mini-volleyball: effect on game performance and knowledge in sport education," Perceptual \& Motor Skills, vol. 128, no. 4, pp. 1851-1871, 2021.

[7] F. R. Javier and C. Ashley, "Sport education as a cooperative learning endeavor," Physical Education and Sport Pedagogy, vol. 26, no. 4, pp. 375-387, 2021.

[8] A. Bengueneb, A. Atallah, and B. Djourdem, "The competence of professors of physical and sports education in the use of modern teaching strategies for middle school under the second generation curriculum," Acta Facultatis Educationis Physicae Universitatis Comenianae, vol. 61, no. 1, pp. 52-61, 2021.

[9] G. A. Alexander, H. Stephen, G. H. Francisco, G. V. Sixto, P. Alba, and M. Alberto, "Effect of a hybrid teaching games for understanding/sport education unit on elementary students' self-determined motivation in physical education," European Physical Education Review, vol. 27, no. 2, pp. 366-383, 2021.

[10] P. M. Federico, M. G. Antonio, D. O. D. Martínez, L. Almond, R. Thorpe, and D. Bunker, "Physical activity levels during a Sport Education season of games from around the world," European Physical Education Review, vol. 27, no. 2, pp. 240-257, 2021.

[11] B. Cristiana, H. Peter, R. Ana, and M. Isabel, "What actually differs between traditional teaching and sport education in students' learning outcomes? A critical systematic review," Journal of Sports Science \& Medicine, vol. 20, no. 1, pp. 110-125, 2021.

[12] B. Cristiana, H. Peter, R. António, and M. Isabel, "Sport education and traditional teaching: influence on students' empowerment and self-confidence in high school physical education classes," Sustainability, vol. 13, no. 2, p. 578, 2021.

[13] R. Abdelaziz, K. SalahEddine, S. Sabah, and A. Boujemaa, "The contribution of physical and sports education to health education of Moroccan middle school students: representations and practices of teachers," Journal of Education and Health Promotion, vol. 10, no. 1, p. 201, 2021.
[14] O. Nejmeddine, O. Hela, A. Amina, Z. Makrem, and B. Anissa, "Practices of didactic interventions in physical and sport education and place of expertise: effective teacher designs and achievements," Creative Education, vol. 11, no. 12, pp. 2846-2854, 2020.

[15] M. Angelo, S. Kelly, and L. Gaudreault Karen, "Enhance student motivation and social skills: adopting the sport education and cooperative learning models," Journal of Physical Education, Recreation and Dance, vol. 91, no. 8, pp. 15-20, 2020.

[16] H. Peter, B. Korey, W. J. Kurt, and S. Andy, "Promoting the 50 million strong agenda through sport education," Journal of Physical Education, Recreation and Dance, vol. 91, no. 8, pp. 8-14, 2020.

[17] S. Harvey, S. Pill, P. Hastie, and T. Wallhead, "Physical education teachers' perceptions of the successes, constraints, and possibilities associated with implementing the sport education model," Physical Education and Sport Pedagogy, vol. 25, no. 5, pp. 555-566, 2020.

[18] C. S. Ming, S. K. W. Raymond, L. F. L. Elean, W. Tristan, M. Kevin, and M. Daniel, "Effect of sports education on students' perceived physical literacy, motivation, and physical activity levels in university required physical education: a cluster-randomized trial," Higher Education, vol. 81, no. 6, pp. 1137-1155, 2020.

[19] S. Smart and Z. Wahl-Alexander, "Optimizing physical activity during non-fitness-based sport education seasons," Journal of Physical Education, Recreation and Dance, vol. 91, no. 4, pp. 22-29, 2020.

[20] P. Hastie, A. Hu, H. Liu, and S. Zhou, "Incorporating Sport Education within a physical education sports club in China," Curriculum Studies in Health and Physical Education, vol. 11, no. 2, pp. 129-144, 2020.

[21] F. Puente-Maxera, A. Méndez-Giménez, and D. Martínez de Ojeda, "Games from around the world: promoting intercultural competence through sport education in secondary school students," International Journal of Intercultural Relations, vol. 75, pp. 23-33, 2020.

[22] A. Gil-Arias, F. Claver, A. Práxedes, F. D. Villar, and S. Harvey, "Autonomy support, motivational climate, enjoyment and perceived competence in physical education: impact of a hybrid teaching games for understanding/sport education unit," European Physical Education Review, vol. 26, no. 1, pp. 36-53, 2020.

[23] K. McEntyre, M. D. Curtner-Smith, and S. A. Wind, "Negotiation patterns of a preservice physical education teacher and his students during sport education," European Physical Education Review, vol. 26, no. 1, pp. 198-217, 2020.

[24] G. Z. Kohe and H. Collison, "Playing on common ground: spaces of sport, education and corporate connectivity, contestation and creativity," Sport in Society, vol. 23, no. 1, pp. 56-71, 2020.

[25] Z. Marta, Z. Abdelkader, and D. H. Saray, "Comparison of sports habits and attitudes in university students of physical and sports education of mostaganem (Algeria) and physical activity and sport sciences of león (Spain)," Frontiers in Psychology, vol. 11, Article ID 593322, 2020.

[26] B. Cristiana, H. Peter, A. Rui, and M. Isabel, "What do we know about the development of personal and social skills within the sport education model: a systematic review," Journal of Sports Science \& Medicine, vol. 18, no. 4, pp. 812-829, 2019. 